\title{
An imbalance in plasma prostanoids in patients with Raynaud's phenomenon and pulmonary vasospasm
}

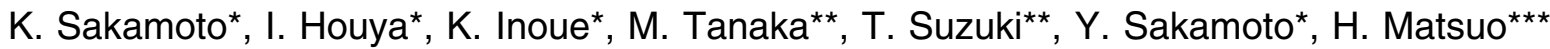

\begin{abstract}
An imbalance in plasma prostanoids in patients with Raynaud's phenomenon and pulmonary vasospasm. K. Sakamoto, I. Houya, K. Inoue, M. Tanaka, T. Suzuki, Y. Sakamoto, H. Matsuo. C) ERS Journals Ltd 1999.

ABSTRACT: Raynaud's phenomenon has been suggested as a predisposing factor for pulmonary vasospasm which may lead to pulmonary hypertension, but the occurrence of cold stimulus-induced pulmonary vasospasm has been inconsistent. Such inconsistent pulmonary vascular responses may be caused by differences in the production of endogenous vasodilators and vasoconstrictors among patients.

Fourteen patients with Raynaud's phenomenon associated with mixed connective tissue disease $(n=10)$ or systemic sclerosis $(n=4)$ participated in the study. Right heart catheterization was performed before and after a cold pressor test, immersing a hand in cold water $\left(\mathrm{15}^{\circ} \mathrm{C}\right)$ for $5 \mathrm{~min}$. Plasma levels of 6-keto prostaglandin (PG)F $\mathrm{F}_{1 \alpha}$, thromboxane (TX)B $B_{2}$ and endothelin (ET)-1 in the mixed venous blood were measured.

Mean pulmonary artery pressure increased after the cold pressor test in five of 14 patients, and the patients were divided into those with pulmonary vasospasm (responders) and those without vasospasm (nonresponders). After the cold pressor test, levels of 6-keto $\mathbf{P G F}_{1 \alpha}$ increased significantly in nonresponders $(p<0.01)$ and decreased significantly in responders $(p<0.05)$. The ratios of 6 -keto $\mathrm{PGF}_{1 \alpha}$ to $\mathrm{TXB}_{2}$ significantly increased in nonresponders $(p<0.01)$ but not in responders and the difference between responders and nonresponders after the cold pressor test was also statistically significant $(p<0.05)$. No significant change in plasma ET-1 levels occurred in either responders or nonresponders.

The results suggest that an impaired production of prostaglandin $I_{2}$ and an imbalance between prostaglandin $I_{2}$ and thromboxane $A_{2}$ are associated with the occurrence of pulmonary vasospasm induced by Raynaud's phenomenon.

Eur Respir J 1999; 13: 137-144.
\end{abstract}

Divisions of $*$ Pulmonology, **Rheumatology and $* * *$ Cardiology, Second Dept of Internal Medicine, Saitama Medical School, Saitama, Japan.

\author{
Correspondence: Y. Sakamoto \\ Second Dept of Internal Medicine \\ Saitama Medical School \\ 38 Morohongo \\ Moroyamacho \\ Irumagun \\ Saitama 350-04 \\ Japan \\ Fax: 81492958399
}

Keywords: Prostaglandin $\mathrm{I}_{2}$

pulmonary vasospasm

Raynaud's phenomenon

thromboxane $\mathrm{A}_{2}$

Received: September 21997

Accepted after revision August 61998

The respiratory system is one of the target organs in collagen vascular diseases, and inflammatory processes with acute or chronic onset occur in the pleura, alveolar walls and vascular beds. Pulmonary hypertension $(\mathrm{PH})$ is frequently encountered in patients with systemic sclerosis (SSc) and mixed connective tissue disease (MCTD) in the absence of discernible changes to the pulmonary parenchyma $[1,2]$. Although the pathogenesis of $\mathrm{PH}$ is still unknown it is speculated that early vasospasm accompanied by a chronic inflammatory process is one of the factors that leads to the development of lung vascular remodelling.

Raynaud's phenomenon is a manifestation of digital vasospasm induced by various stimuli including cold exposure and is frequently seen in patients with SSc and MCTD. Such a vasospastic tendency is not restricted to the digits, but also occurs in the internal organs such as the kidneys [3] and heart [4], suggesting that Raynaud's phenomenon represents a generalized vasospastic predisposition. Patients who are prone to show Raynaud's phenomenon may also have acute spasm of the pulmonary circulation, and repeated episodes of pulmonary vasospasm may cause irreversible structural changes to the vessels, leading to persistent PH. In this context, Raynaud's phenomenon is observed in about $10 \%$ of patients with primary $\mathrm{PH}(\mathrm{PPH})$ [5]. From this point of view, some investigators have reported that a reduction in pulmonary blood flow followed cold water-induced digital vasospasm $[6,7]$; however, an argument against this has also been reported [8]. Thus, the relationship between digital vasospasm and pulmonary vasospasm remains unclear.

Vascular tone is regulated by the sympathetic nervous system and vasoactive substances. The cold pressor test induces an increase in prostaglandin $(\mathrm{PG}) \mathrm{I}_{2}$ and $\mathrm{PGE}_{2}$ in coronary arterial blood in healthy subjects but not in patients with angina pectoris [9]. The cold pressor test also induces increases in serum endothelin (ET)-1 in patients with primary Raynaud's phenomenon [10]. These reports suggest that an imbalance between vasodilators and vasoconstrictors generated endogenously after a cold stimulus may be a key factor for the occurrence of vasospasm. In this context, an increase in the generation of thromboxane (TX) $\mathrm{A}_{2}$ and the decrease in that of $\mathrm{PGI}_{2}$ has been reported in patients with PPH [11].

The aim of this study was to test the hypothesis that the difference in the balance of vasoactive substances generated after a cold stimulus determines the occurrence of pulmonary vasospasm. For this purpose changes in haemodynamics and in plasma levels of ET-1 and metabolites of $\mathrm{PGI}_{2}$ and $\mathrm{TXA}_{2}$ during the cold pressor test were examined in patients with SSc or MCTD. 


\section{Patients}

\section{Methods}

Fourteen patients, 10 with MCTD and four with SSc (13 females) aged $24-66$ yrs $(48 \pm 12$, mean \pm SD), were studied. Among the 13 females, four of nine patients with MCTD and three of four with SSc were postmenopausal. None of the patients had ever smoked or received corticosteroids or vasoactive agents. The criteria for MCTD described by PORTER et al. [12] or that for SSc by the American College of Rheumatology (formerly the American Rheumatism Association) [13] was fulfilled in every patient. All patients except for two showed no abnormal findings on physical examination of the chest, chest radiography and high-resolution computed tomography (HRCT) films. Two patients with SSc (numbers 11 and 12) demonstrated obvious pulmonary fibrosis: both had bibasilar late-inspiratory fine crackles on chest examination. Chest radiography showed a loss of volume and bibasilar reticular infiltrates with honeycombing in patient number 11 and bibasilar reticular infiltrates in number 12. HRCT scans further revealed ground-glass opacification with extensive honeycombing in number 11 and patchy peripheral honeycombing in number 12 . Judging from these radiographic findings and the results of pulmonary function tests mentioned below, pulmonary fibrosis was severe in patient number 11 and mild in number 12. The details of the patients' characteristics are described in table 1. Every patient gave informed consent before the study.

\section{Pulmonary function tests}

Pulmonary function tests, including the lung carbon monoxide diffusing capacity $(D \mathrm{~L}, \mathrm{CO})$, were performed using an automatic spirometer (PK Morgan, Kent, UK) in the sitting position with a noseclip in place. $D$ L,CO was measured by a standardized single-breath technique [14]. Heparinized arterial blood was drawn from the radial artery and used for blood gas analysis. The predicted value for vital capacity (VC) was calculated by the equation described by BALDWIN et al. [15]. To calculate the predicted value for DL,CO, three different equations described by NishiDA et al. [16], YANG et al. [17] and CRAPO and MORRIS [18] were used, since predicted values vary somewhat among equations, partly due to differences in the populations used. The details of the patients' functional characteristics are described in table 2 .

\section{Cold pressor test and right heart catheterization}

Patients were studied in the supine position. A 7.5 F Swan-Ganz catheter (Baxter Healthcare Co., Irvine, CA, USA) was inserted into the femoral vein under local anaesthesia and advanced into the pulmonary artery. The zero point was determined to a point $5 \mathrm{~cm}$ below the sternal notch. Cardiac output was measured by the thermodilution technique. Pulmonary capillary wedge pressure, all right-sided pressures and cardiac output were measured using transducers linked to modules and a recorder (Fukuda Electronics, Tokyo, Japan). Pulmonary vascular resistance (PVR) was calculated according to a standard formula. $\mathrm{PH}$ was defined as a mean pulmonary artery pressure (mPAP) $>20 \mathrm{mmHg}$. The monitoring of systemic arterial pressure using an indwelling arterial catheter was avoided in order to minimize the influence of the puncture procedure on the local or systemic vascular tone which may alter the haemodynamic condition and vasoactive substance levels at baseline. Indirect measurement of blood pressure at the brachial artery was performed using an automatic sphygmomanometer (Colin, Komaki, Japan).

Each patient was kept at room temperature $\left(22-25^{\circ} \mathrm{C}\right)$ for $20 \mathrm{~min}$ in the baseline condition, then a test hand was immersed to wrist level in a waterbath of $15^{\circ} \mathrm{C}$ for $5 \mathrm{~min}$. The electrocardiogram and PAP were recorded continuously throughout the study. When the fluctuations in cardiac frequency and PAP became stable in the baseline condition and during the cold pressor test, blood sampling and measurements of other haemodynamic parameters were performed. Mixed venous blood samples were obtained from a branch of the pulmonary artery before the measurement of haemodynamic parameters to minimize the effect of mechanical stimulation of pulmonary arterial endothelium on the levels of vasoactive substances. Simultaneous blood collection from a systemic artery by the puncture was not performed, for the same reason mentioned in the above paragraph. At the end of the study heparinized arterial blood was drawn from the radial artery for gas

Table 1. - Clinical characteristics of patients

\begin{tabular}{|c|c|c|c|c|c|c|c|c|c|c|}
\hline \multirow[t]{2}{*}{ Disease } & \multirow{2}{*}{$\begin{array}{c}\text { Patient } \\
\text { No. }\end{array}$} & \multirow{2}{*}{$\begin{array}{l}\text { Age } \\
\text { yrs }\end{array}$} & \multirow[t]{2}{*}{ Sex } & \multirow[t]{2}{*}{ Menopause } & \multirow{2}{*}{$\begin{array}{c}\text { Height } \\
\mathrm{cm}\end{array}$} & \multirow{2}{*}{$\begin{array}{c}\text { Weight } \\
\mathrm{kg}\end{array}$} & \multirow{2}{*}{$\begin{array}{c}\text { Duration of } \\
\text { disease } \\
\text { yrs }\end{array}$} & \multicolumn{2}{|c|}{ Antinuclear antibody } & \multirow{2}{*}{$\begin{array}{l}\text { Titre of } \\
\text { anti-RNP } \\
\text { antibody }\end{array}$} \\
\hline & & & & & & & & Titre & Pattern & \\
\hline \multirow[t]{10}{*}{ MCTD } & 1 & 42 & $\mathrm{~F}$ & Pre & 151.0 & 44.0 & 8 & $1: 5120$ & $\mathrm{sp}$ & $1: 163820$ \\
\hline & 2 & 56 & $\mathrm{~F}$ & Post & 148.0 & 38.5 & 13 & $1: 320$ & $\mathrm{sp}$ & $1: 163840$ \\
\hline & 3 & 29 & $\mathrm{~F}$ & Pre & 153.0 & 51.5 & 12 & $1: 5120$ & $\mathrm{sp}$ & $1: 163840$ \\
\hline & 4 & 51 & $\mathrm{~F}$ & Post & 160.0 & 55.0 & 1 & $1: 320$ & $\mathrm{sp}$ & $1: 81290$ \\
\hline & 5 & 48 & $\mathrm{M}$ & & 164.5 & 65.0 & 15 & $1: 5120$ & $\mathrm{sp}$ & $1: 256000$ \\
\hline & 6 & 24 & $\mathrm{~F}$ & Pre & 152.0 & 56.0 & 10 & $1: 5120$ & $\mathrm{sp}$ & $1: 81920$ \\
\hline & 7 & 60 & $\mathrm{~F}$ & Post & 148.5 & 41.0 & 15 & $1: 5120$ & $\mathrm{sp}$ & $1: 81920$ \\
\hline & 8 & 62 & $\mathrm{~F}$ & Post & 145.0 & 40.0 & 10 & $1: 5120$ & $\mathrm{sp}$ & $1: 20480$ \\
\hline & 9 & 41 & $\mathrm{~F}$ & Pre & 153.0 & 63.0 & 3 & $1: 2560$ & $\mathrm{sp}$ & $1: 81920$ \\
\hline & 10 & 40 & $\mathrm{~F}$ & Pre & 163.0 & 68.5 & 2 & $1: 5120$ & $\mathrm{sp}$ & $1: 81920$ \\
\hline \multirow[t]{4}{*}{$\mathrm{SSc}$} & 11 & 45 & $\mathrm{~F}$ & Pre & 161.5 & 59.5 & 2 & $1: 1640$ & $\mathrm{sp}$ & Negative \\
\hline & 12 & 60 & $\mathrm{~F}$ & Post & 158.0 & 48.5 & $<0.1$ & Negative & & Negative \\
\hline & 13 & 66 & $\mathrm{~F}$ & Post & 145.0 & 39.0 & $<0.1$ & $1: 640$ & $\mathrm{~h}$ & Negative \\
\hline & 14 & 54 & $\mathrm{~F}$ & Post & 154.0 & 56.0 & 7 & $1: 80$ & $\mathrm{~h}$ & Negative \\
\hline
\end{tabular}

RNP: ribonucleoprotein; MCTD: mixed connective tissue disease; SSc: systemic sclerosis; F: female; M: male; sp: speckled; h: homogenous. 
Table 2. - Functional characteristics of patients

\begin{tabular}{|c|c|c|c|c|c|c|c|c|c|}
\hline \multirow[t]{2}{*}{ Disease } & \multirow{2}{*}{$\begin{array}{l}\text { Patient } \\
\text { No. }\end{array}$} & \multirow{2}{*}{$\begin{array}{l}\mathrm{VC} \\
\% \text { pred }\end{array}$} & \multirow{2}{*}{$\underset{\%}{\mathrm{FEV} 1}$} & \multicolumn{4}{|c|}{$D \mathrm{~L}, \mathrm{CO}$} & \multirow[t]{2}{*}{$\begin{array}{l}\mathrm{Pa}, \mathrm{O}_{2} \\
\mathrm{mmHg}\end{array}$} & \multirow[t]{2}{*}{$\begin{array}{l}P \mathrm{a}, \mathrm{CO}_{2} \\
\mathrm{mmHg}\end{array}$} \\
\hline & & & & $\begin{array}{c}\text { Actual } \\
\mathrm{mL} \cdot \mathrm{min}^{-1} \cdot \mathrm{mmHg}^{-1}\end{array}$ & $\begin{array}{c}\text { A } \\
\% \text { pred }\end{array}$ & $\begin{array}{c}\mathrm{B} \\
\% \text { pred }\end{array}$ & $\begin{array}{c}\mathrm{C} \\
\% \text { pred }\end{array}$ & & \\
\hline \multirow[t]{10}{*}{ MCTD } & 1 & 123.9 & 83.1 & 17.92 & 83.0 & 100.5 & 73.9 & 101.2 & 34.5 \\
\hline & 2 & 114.6 & 87.6 & 14.00 & 68.7 & 97.0 & 65.2 & 87.7 & 32.5 \\
\hline & 3 & 112.6 & 88.9 & 12.14 & 53.6 & 57.4 & 45.6 & 113.4 & 33.3 \\
\hline & 4 & 122.9 & 80.2 & 18.41 & 82.4 & 97.8 & 72.9 & 76.0 & 34.9 \\
\hline & 5 & 85.8 & 77.7 & 16.77 & 61.9 & 69.5 & 53.1 & 112.5 & 40.2 \\
\hline & 6 & 96.9 & 89.5 & 12.96 & 56.9 & 57.9 & 47.8 & 79.2 & 33.0 \\
\hline & 7 & 94.4 & 91.3 & 8.35 & 41.3 & 59.2 & 39.7 & 101.9 & 33.0 \\
\hline & 8 & 89.3 & 63.2 & 8.74 & 44.5 & 66.4 & 44.1 & 112.2 & 23.8 \\
\hline & 9 & 99.6 & 79.6 & 10.78 & 49.1 & 52.8 & 43.3 & 102.4 & 28.3 \\
\hline & 10 & 124.6 & 84.8 & 16.41 & 69.8 & 72.4 & 59.2 & 71.3 & 29.6 \\
\hline \multirow[t]{4}{*}{$\mathrm{SSc}$} & 11 & 50.5 & 86.4 & 6.55 & 28.6 & 31.9 & 24.7 & 74.4 & 30.4 \\
\hline & 12 & 80.3 & 76.1 & 12.60 & 58.6 & 77.4 & 53.7 & 109.0 & 32.3 \\
\hline & 13 & 105.0 & 70.4 & 11.80 & 60.8 & 95.2 & 61.3 & 121.8 & 29.8 \\
\hline & 14 & 104.4 & 76.7 & 7.88 & 36.9 & 44.8 & 33.8 & 85.1 & 29.8 \\
\hline
\end{tabular}

VC: vital capacity; FEV1: forced expiratory volume in one second; DL,CO: diffusing capacity of the lung for carbon monoxide. (Equations by A: Nishida et al. [16]; B: YANG et al. [17]; C: Crapo and Morris [18].) Pa, $\mathrm{O}_{2}$ : arterial oxygen tension; $P$ a, $\mathrm{CO}_{2}$ : arterial carbon dioxide tension $(1 \mathrm{mmHg}=0.133 \mathrm{kPa})$; MCTD: mixed connective tissue disease; SSc: systemic sclerosis.

analysis. Mixed venous blood was transferred into a tube containing indomethacin for the measurement of prostanoids and another tube containing aprotinin and ethylenediaminetetraacetic acid (EDTA) for the measurement of ET-1, kept on ice, then immediately centrifuged at 2,500$\times g$ for $10 \mathrm{~min}$ at $4^{\circ} \mathrm{C}$. Plasma was transferred into polypropylene tubes and kept at $-80^{\circ} \mathrm{C}$ until assayed.

Measurement of 6-keto prostaglandin $F_{1 \alpha}$ and thromboxane $B_{2}$

The prostanoid-rich fraction was extracted according to the method described by Powell [19]. Plasma was acidified with $1 \mathrm{~N} \mathrm{HCl}$ to $\mathrm{pH} 3.0$, then passed through a Sep-Pak $\mathrm{C}_{18}$ column (Waters Associates, Milford, MA, USA) pretreated with methanol and distilled water. After washing with distilled water, $10 \%$ ethanol and hexane, the prostanoid-rich fraction was eluted with methyl formate and evaporated under $\mathrm{N}_{2}$ gas. The residue was dissolved in assay buffer, and levels of 6-keto $\mathrm{PGF}_{1 \alpha}$ and $\mathrm{TXB}_{2}$ were determined using radioimmunoassaykits(Amersham,Buckinghamshire,UK). All samples were assayed simultaneously in duplicate. Preliminary experiments demonstrated that the intra- and interassay coefficients of variation in the determination of 6-keto $\mathrm{PGF}_{1 \alpha}$ or $\mathrm{TXB}_{2}$ were $<5 \%$ and $10 \%$, respectively.

\section{Measurement of endothelin-1}

ET-1 was assayed according to the method described previously [20]. Plasma mixed with three volumes of $4 \%$ acetic acid was applied to a Sep-Pak $\mathrm{C}_{18}$ column pretreated with ethanol containing $4 \%$ acetic acid, methanol, distilled water, then $4 \%$ acetic acid. After washing with $4 \%$ acetic acid and distilled water, the ET-rich fraction was eluted with ethanol containing $4 \%$ acetic acid. The fraction was evaporated under $\mathrm{N}_{2}$ gas, dissolved with $1 \mathrm{~mL}$ ethanol, then evaporated again. The residue was dissolved in $50 \mathrm{mM}$ Good's buffer, $\mathrm{pH} 8.0$, then ultrasonicated for $10 \mathrm{~min}$ at $37^{\circ} \mathrm{C}$. After centrifugation at $10,000 \times g$ for 5 min, the supernatant was collected. The levels of ET-1 were determined using an ET-1 enzyme-linked immunosorbent assay (ELISA) kit (Wako, Tokyo, Japan). All samples were assayed simultaneously in duplicate. Preliminary experiments showed that the intra- and interassay coefficients of variation in the determination of ET- 1 were $<5 \%$ and $15 \%$, respectively.

All assays were performed by an operator without knowledge of the protocol and the derivation of each sample.

\section{Statistical analysis}

The data were expressed as mean \pm SEM and median. Because the number of patients was small, statistical analysis was performed using nonparametric methods. Comparisons between the groups were made with the Mann-Whitney U-test. The Wilcoxon signed rank test was used to compare the results obtained before and after the cold pressor test in each group. The Chi-squared test was used to compare the frequency of menopause between the groups. A p-value $<0.05$ was considered statistically significant.

\section{Results}

\section{Changes in haemodynamic parameters}

The haemodynamic parameters before the cold pressor test are listed in table 3 . Three patients (numbers 5, 11 and 14) had a mPAP $>20 \mathrm{mmHg}$. Two patients with MCTD (numbers 7 and 8) showed relatively low cardiac output in the absence of elevated pulmonary wedge pressure.

After the cold pressor test mPAP increased by 3-5 $\mathrm{mmHg}$ in five of 14 patients (numbers 3, 6, 8, 10 and 12) (fig. 1). Patients were divided into two groups: patients who showed elevated mPAP after the cold pressor test were designated as responders $(n=5)$ while those who failed to show the mPAP elevation were designated as nonresponders $(n=9)$. The changes in other haemodynamic parameters and vasoactive prostanoids were compared between the two groups.

In accordance with the increase in mPAP, PVR increased after the cold pressor test in all responders, from 114 \pm 19 (107) (mean \pm SEM (median)) to $140 \pm 22$ (142) dyne.s. $\mathrm{cm}^{-5} \cdot \mathrm{m}^{2}$ and this increase was statistically significant $(\mathrm{p}<$ 0.05 ) (fig. 2). Meanwhile, PVR changed from 168 \pm 34 (135) to $156 \pm 29$ (129) dyne $\cdot \mathrm{s} \cdot \mathrm{cm}^{-5} \cdot \mathrm{m}^{2}$ in nonresponders 
Table 3. - Haemodynamics before the cold pressor test

\begin{tabular}{|c|c|c|c|c|c|c|}
\hline Disease & $\begin{array}{l}\text { Patient } \\
\text { No. }\end{array}$ & $\begin{array}{l}\text { Mean pulmonary } \\
\text { artery pressure } \\
\text { mmHg }\end{array}$ & $\begin{array}{c}\text { Mean pulmonary } \\
\text { wedge pressure } \\
\mathrm{mmHg}\end{array}$ & $\begin{array}{c}\text { Mean systemic } \\
\text { artery pressure } \\
\text { mmHg }\end{array}$ & $\begin{array}{l}\text { Cardiac output } \\
\mathrm{L} \cdot \mathrm{min}^{-1}\end{array}$ & $\begin{array}{c}\text { Pulmonary vascular } \\
\text { resistance } \\
\text { dyne } \cdot \mathrm{s} \cdot \mathrm{cm}^{-5} \cdot \mathrm{m}^{2}\end{array}$ \\
\hline \multirow[t]{10}{*}{ MCTD } & 1 & 7 & 2 & 70 & 4.29 & 93.2 \\
\hline & 2 & 9 & 2 & 114 & 4.74 & 134.9 \\
\hline & 3 & 11 & 4 & 83 & 5.84 & 109.5 \\
\hline & 4 & 8 & 3 & 114 & 5.90 & 67.7 \\
\hline & 5 & 22 & 13 & 95 & 5.49 & 116.5 \\
\hline & 6 & 15 & 7 & 72 & 6.72 & 107.0 \\
\hline & 7 & 7 & 2 & 119 & 3.37 & 166.0 \\
\hline & 8 & 6 & 2 & 108 & 2.34 & 136.6 \\
\hline & 9 & 9 & 0 & 100 & 7.24 & 110.4 \\
\hline & 10 & 8 & 6 & 100 & 5.70 & 56.0 \\
\hline \multirow[t]{4}{*}{ SSc } & 11 & 28 & 4 & 118 & 5.43 & 36.80 \\
\hline & 12 & 14 & 5 & 83 & 4.73 & 169.0 \\
\hline & 13 & 10 & 0 & 85 & 5.83 & 150.8 \\
\hline & 14 & 25 & 7 & 125 & 4.18 & 305.4 \\
\hline
\end{tabular}

MCTD: mixed connective tissue disease; SSc: systemic sclerosis.

and no statistically significant difference was found. Cardiac output increased in two responders and two nonresponders and no statistically significant change after the cold pressor test was found in either group (5.1 \pm 0.8 (5.7) to $5.4 \pm 0.6(5.9) \mathrm{L} \cdot \mathrm{min}^{-1}$ in responders, and $5.2 \pm 0.4(5.4)$ to $5.0 \pm 0.5(5.6) \mathrm{L} \cdot \mathrm{min}^{-1}$ in nonresponders). The mean systemic blood pressure increased in one of the responders and two of the nonresponders and no statistically significant change occurred in either group $(89 \pm 7$ (83) to $88 \pm 6$ (85) $\mathrm{mmHg}$ in responders and $104 \pm 6(114)$ to $102 \pm 8$ (110) $\mathrm{mmHg}$ in nonresponders). After the cold pressor test, the levels of arterial oxygen tension $\left(\mathrm{Pa}, \mathrm{O}_{2}\right)$ were $13.7 \pm 1.2$ $(13.0) \mathrm{kPa}(103 \pm 9(98) \mathrm{mmHg})$ in responders and $13.3 \pm$ $0.8(13.7) \mathrm{kPa}(100 \pm 6(103) \mathrm{mmHg})$ in nonresponders and no statistically significant difference was found between the groups.

Changes in plasma levels of 6-keto prostaglandin $1 \alpha$, thromboxane $B_{2}$ and endothelin-1

There was no statistically significant difference in plasma levels of 6-keto $\mathrm{PGF}_{1 \alpha}$ between responders and nonre-

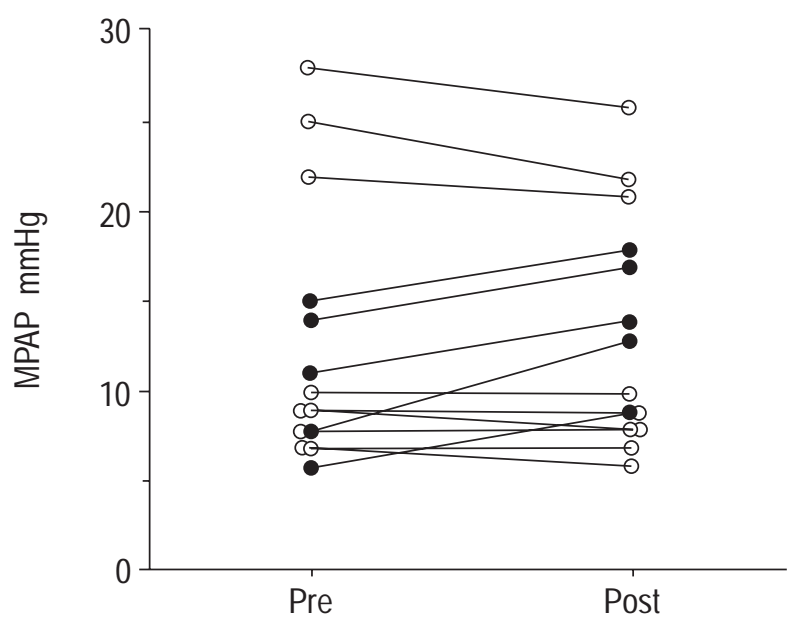

Fig. 1. - Changes in mean pulmonary artery pressure (MPAP) before (Pre) and after (Post) the cold pressor test. $\bullet$ : patients with an increase in MPAP $(n=5)$; and $\bigcirc$ : patients with no increase in MPAP after the cold pressor test $(n=9)$. sponders before the cold pressor test. The levels of 6-keto $\mathrm{PGF}_{1 \alpha}$ before and after the cold pressor test in responders were $435 \pm 90(355)$ and $325 \pm 49(325) \mathrm{pg} \cdot \mathrm{mL}^{-1}$, respectively, and this decrease was statistically significant $(\mathrm{p}<0.05)$ (fig. 3). The levels before and after the cold pressor test were $342 \pm 54(290)$ and $536 \pm 71(470) \mathrm{pg} \cdot \mathrm{mL}^{-1}$, respectively, in nonresponders and this increase was also statistically significant $(\mathrm{p}<0.01)$.

There was no statistically significant difference in plasma levels of $\mathrm{TXB}_{2}$ between responders and nonresponders before the cold pressor test. After the test the changes in levels of $\mathrm{TXB}_{2}$ were variable in responders, decreasing in four patients and increasing in one. The levels before and after the cold pressor test were $266 \pm 47$ (268) and $222 \pm 32$ (232) $\mathrm{pg} \cdot \mathrm{mL}^{-1}$, respectively, and no statistically significant difference was found. Meanwhile, the levels of $\mathrm{TXB}_{2}$ decreased in all nonresponders but one. The mean levels before and after the cold pressor test were $263 \pm 26$ (260) and $174 \pm 33(172) \mathrm{pg} \cdot \mathrm{mL}^{-1}$, respectively, and the decrease in the levels of $\mathrm{TXB}_{2}$ after the cold pressor test was statistically significant $(\mathrm{p}<0.05)$.

To evaluate the changes in the balance between the vasodilator and the vasoconstrictor, the ratios of 6-keto $\mathrm{PGF}_{1 \alpha}$ to $\mathrm{TXB}_{2}$ were compared. In responders the ratios before and after the cold pressor test were $1.94 \pm 0.52$ (2.46) and $1.65 \pm 0.37$ (2.05), respectively. The change was minimal in each individual and no statistically significant difference was found. In contrast, the ratios before and after the cold pressor test in nonresponders were $1.46 \pm 0.30$ (1.32) and 5.00 2.07 (3.08), respectively. The ratios increased in most individuals and this increase was statistically significant $(\mathrm{p}<0.01)$. A statistically significant difference in the ratios after the cold pressor test also occurred between responders and nonresponders $(\mathrm{p}<0.05)$.

Plasma ET-1 levels before and after the cold pressor test were $0.94 \pm 0.16(0.88)$ and $0.87 \pm 0.20(0.80) \mathrm{pg} \cdot \mathrm{mL}^{-1}$ in responders, and $0.83 \pm 0.12(0.75)$ and $0.80 \pm 0.09(0.90)$ $\mathrm{pg} \cdot \mathrm{mL}^{-1}$ in nonresponders, respectively. No statistically significant change in the levels of ET-1 during the cold pressor test was found in either group and no statistically significant difference was found between responders and nonresponders. 

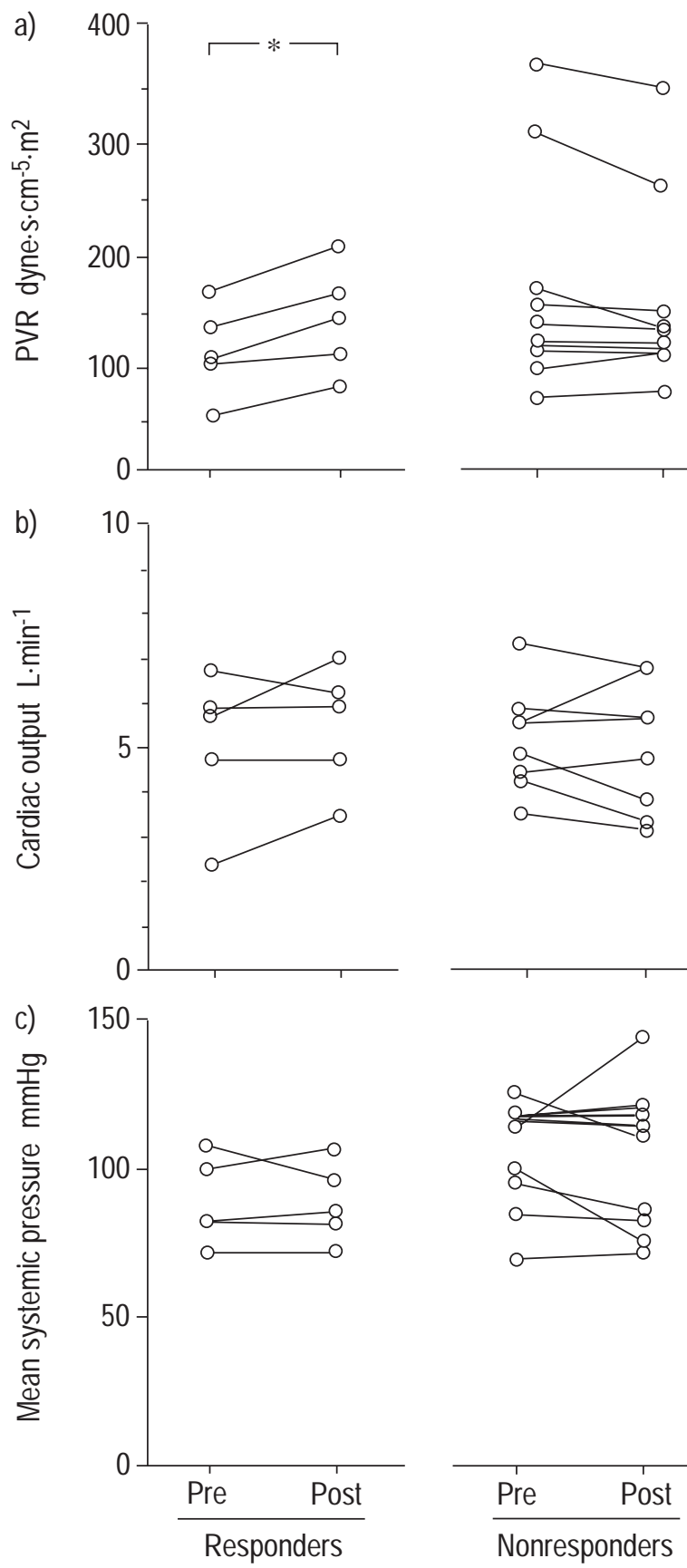

Fig. 2. - Comparison of changes in a) pulmonary vascular resistance (PVR), b) cardiac output and c) mean systemic pressure, before (Pre) and after (Post) the cold pressor test, between responders and nonresponders. $*: \mathrm{p}<0.05$.

Plasma levels of 6-keto $\mathrm{PGF}_{1 \alpha}, \mathrm{TXB}_{2}$ and ET-1 before the cold pressor test were compared between patients who showed mPAP $>20 \mathrm{mmHg}$ at stable baseline $(\mathrm{n}=3)$ and others with normal mPAP $(\mathrm{n}=11)$. Plasma levels and the ratios of 6-keto $\mathrm{PGF}_{1 \alpha}$ to $\mathrm{TXB}_{2}$ in these three patients were within the ranges in patients with normal mPAP (data not shown).

\section{Discussion}

In the present study pulmonary vasospasm was provoked in approximately one-third of the patients with MCTD or SSc. Reports of the occurrence of pulmonary vasospasm due to cold stimulus in patients with primary or secondary Raynaud's phenomenon differ among investigators. BARR and FAHEY [7] reported a decrease in lung diffusing capacity in eight of 12 patients and they attributed the mechanism to the reduction of pulmonary capillary blood volume. Furst et al. [6] demonstrated a decrease in pulmonary perfusion by krypton perfusion lung scanning in five of nine patients. In contrast, SHUCK et al. [8] measured haemodynamics in nine patients with $\mathrm{SSc}$ and concluded that pulmonary vasospasm was not significantly induced by cold water hand-immersion, suggesting that Raynaud's phenomenon was unlikely to play a major role in the development of PH. Thus, the issue is still controversial. The conditions of the cold pressor test among these investigators were similar: one or both hands were immersed in $10-15^{\circ} \mathrm{C}$ cold water for $2-10 \mathrm{~min}$. Thus, the possibility that the discrepancy among the above reports was caused by differences in the conditions of the cold pressor test is negligible. The reports by BARR and FAHEY [7] and Furst et al. [6] indicated that all patients did not show reduced pulmonary circulation due to the cold pressor test. Even in the study by SHUCK et al. [8], some patients seem to have shown an increase in mPAP and/or PVR. Therefore, it was hypothesized that there exists a heterogeneity in the pulmonary vascular response to cold stimulus, even among patients with similar clinical backgrounds.

The factors determining such a heterogeneity, however, seem complex. Cold stimulus affects vascular tone through $\alpha$-adrenergic stimulation. Since pulmonary vessels receive a plentiful supply of sympathetic nerve fibres, exaggerated stimulation of sympathetic nerves and/or altered adrenoreceptor density may lead to pulmonary vasospasm in some patients with Raynaud's phenomenon. Such sympathetic hyperreactivity has been suggested in patients with systemic hypertension [21], but not in those with Raynaud's phenomenon.

A number of recent works has been clarifying the roles of vasoactive substances as mediators in the regulation of vascular tone. $\mathrm{PGI}_{2}, \mathrm{PGE}_{2}$ and nitric oxide are listed as representative vasodilators, and TXA 2 and ET-1 as vasoconstrictors. An involvement of neuropeptides such as substance $\mathrm{P}$ and calcitonin gene-related peptide in the regulation of vascular tone has also been suggested [22]. The elevation of factor VIII/von Willebrand factor antigen and von Willebrand factor activity in blood has been found in patients with primary Raynaud's phenomenon and SSc, suggesting the presence of endothelial damage [23]. Vascular endothelial cells synthesize $\mathrm{PGI}_{2}, \mathrm{PGE}_{2}$, ET-1 and NO. If endothelial damage occurs, it would lead to the impaired generation of vasoconstrictors and vasodilators. Intravascular activation of platelets accompanied by endothelial damage would also result in the local release of vasoconstrictors such as $\mathrm{TXA}_{2}$ and serotonin. In this context, several studies have shown evidence for pulmonary sequestration of platelets in patients with PPH [24] and platelet abnormalities in patients with Raynaud's phenomenon, especially SSc [25]. Increased urinary levels of a $\mathrm{TXA}_{2}$ metabolite as well as decreased levels of 6-keto $\mathrm{PGF}_{1 \alpha}$ in patients with PPH were reported by CHRISTMAN et al. [11]. Thus, the heterogeneity in the pulmonary vascular response for cold stimulus is possibly determined by enhanced production of vasoconstrictor(s), reduced 

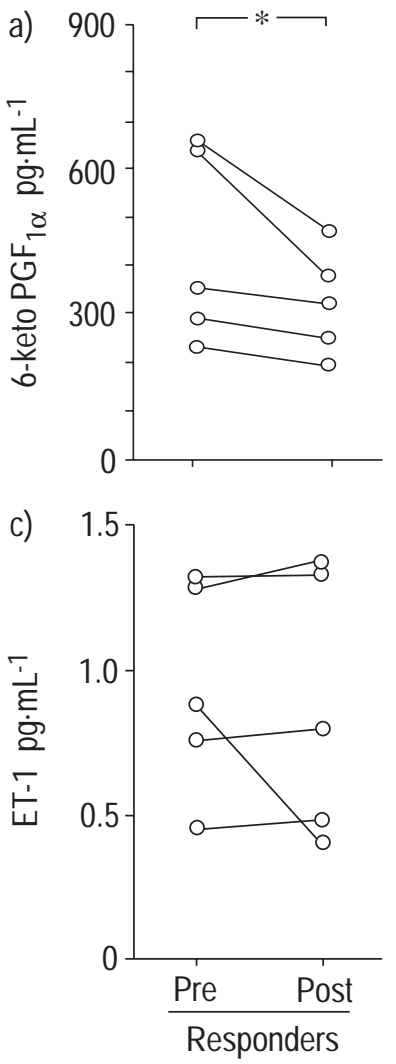
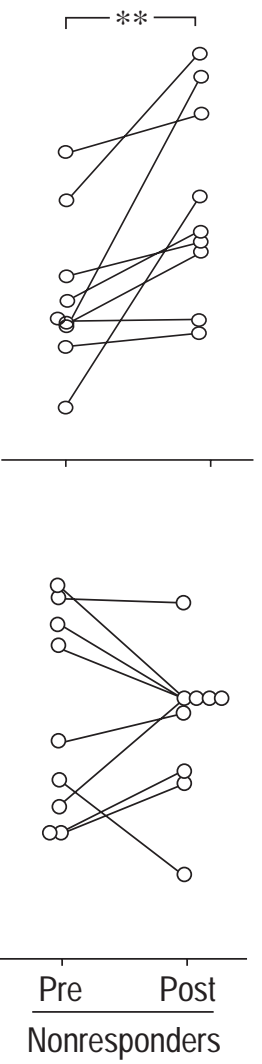
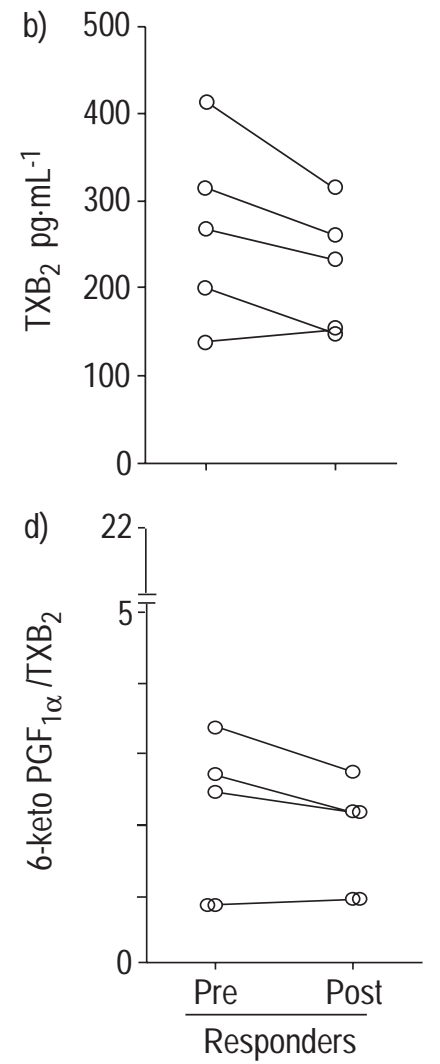
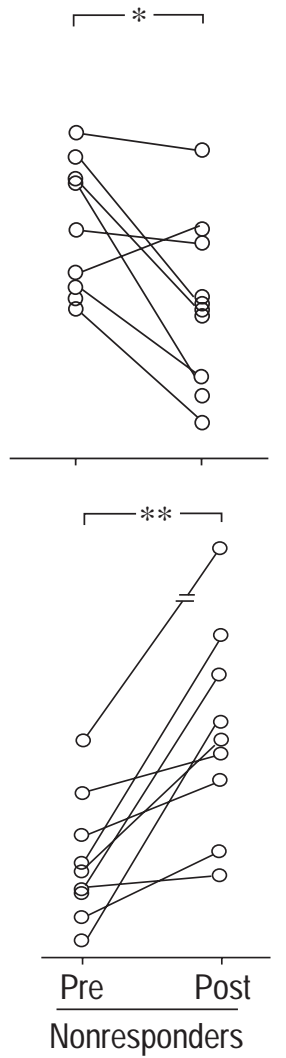

Fig. 3. - Comparison of changes in plasma levels of a) 6-keto prostaglandin (PG) $\mathrm{F}_{1 \alpha}$, b) thromboxane (TX)B $\mathrm{B}_{2}$ and c) endothelin (ET)-1 and d) ratios of 6-keto $\mathrm{PGF}_{1 \alpha}$ to $\mathrm{TXB}_{2}$, before (Pre) and after (Post) the cold pressor test in responders and nonresponders. *: $\mathrm{p}<0.05 ; * *: \mathrm{p}<0.01$.

production of vasodilator(s) or a relative imbalance between vasoconstrictor(s) and vasodilator(s), according to the degree of pre-existing vascular damage. The present data demonstrated that the levels of 6-keto $\mathrm{PGF}_{1 \alpha}$ in the mixed venous blood did not differ between responders and nonresponders at the stable baseline; however, they increased significantly during cold stimulus in nonresponders and decreased in responders. The ratios of 6-keto $\mathrm{PGF}_{1 \alpha}$ to $\mathrm{TXB}_{2}$ also significantly increased in nonresponders but not in responders. These data suggest that the impaired production of vasodilators such as $\mathrm{PGI}_{2}$ is a primary factor in cold stimulus-induced pulmonary vasospasm, which may also be influenced by the imbalance between vasodilators and vasoconstrictors such as $\mathrm{TXA}_{2}$. However, since the number of patients was small, this conclusion should be strengthened by further study.

Basal plasma levels of $\mathrm{PGI}_{2}$ and $\mathrm{TXA}_{2}$ may influence the vascular tone at the stable baseline as well as the response to cold stimulus. In the present study it is unknown whether basal levels of 6-keto $\mathrm{PGF}_{1 \alpha}$ and $\mathrm{TXB}_{2}$ in the mixed venous blood were low or high compared with those in healthy subjects. However, our unpublished data showed that the levels of 6-keto $\mathrm{PGF}_{1 \alpha}$ and $\mathrm{TXB}_{2}$ were $404 \pm 38$ $\mathrm{pg} \cdot \mathrm{mL}^{-1}$ and $190 \pm 12 \mathrm{pg} \cdot \mathrm{mL}^{-1}$, and the ratio of 6-keto $\mathrm{PGF}_{1 \alpha}$ to $\mathrm{TXB}_{2}$ was $2.22 \pm 0.18$ in patients with chronic obstructive pulmonary disease (COPD) without PH $(n=19)$. These values were not significantly different from those in responders or nonresponders, suggesting that the levels of 6-keto $\mathrm{PGF}_{1 \alpha}$ and $\mathrm{TXB}_{2}$ were unlikely to be abnormal at the stable baseline in the present study. In addition, spon- taneous variations in vasoactive substances during the stable baseline were $<5 \%$ for 6 -keto $\mathrm{PGF}_{1 \alpha}$ and $\mathrm{TXB}_{2}$ and $<10 \%$ for ET-1 in that study, suggesting that the levels of substances were likely to be stable with little fluctuation in the stable baseline.

ZAMORA et al. [10] reported that serum ET-1 levels increased after the cold pressor test in patients with primary Raynaud's phenomenon; however, no such increase in plasma ET-1 levels was observed in the present study. This discrepancy is likely to be attributable to the difference in the duration of the cold pressor test: in the present study the cold pressor test was performed at $15^{\circ} \mathrm{C}$ for $5 \mathrm{~min}$, whereas ZAMORA et al. [10] performed it by cooling the temperature in $5^{\circ} \mathrm{C}$ decrements every $5 \mathrm{~min}$ from $40^{\circ} \mathrm{C}$ to $10^{\circ} \mathrm{C}$. In vascular endothelial cells, agonists usually induce the expression of prepro-ET-1 messenger ribonucleic acid (mRNA) within 5 min, reaching a peak by $30-60 \mathrm{~min}$ [26, 27]. The mRNA expression is followed by a gradual increase in ET-1 secretion, reaching a peak by $12-24 \mathrm{~h}$. Thus, a short period, e.g. $5 \mathrm{~min}$, of cold stimulus does not seem to be enough to induce a detectable increase in plasma ET-1 level, indicating that the pulmonary vasospasm observed in the present study was not mediated by ET-1. ZAMORA et al. [10] also showed that ET-1 levels were higher in blood obtained from an arm immersed in cold water than from the contralateral arm. This suggests that the $\mathrm{PGI}_{2}$ increases in the mixed venous blood also originated from the cold water-immersed arm in the present study. However, the possibility of local production of $\mathrm{PGI}_{2}$ in the pulmonary artery cannot be neglected since the local 
production of $\mathrm{PGI}_{2}$ and $\mathrm{PGE}_{2}$ in the coronary artery after the cold pressor test has been reported [9]. This possibility was not confirmed in the present study as the levels of 6keto $\mathrm{PGF}_{1 \alpha}$ in the systemic artery were not measured to estimate the transpulmonary gradient.

The patients defined as responders showed a $3-5 \mathrm{mmHg}$ rise in mPAP during the cold pressor test. As far as we know, no criteria for the judgement of the pulmonary vasospasm provocation test have been reported. Nonetheless, the result that all patients defined as responders also showed significant rise in PVR by the cold pressor test, whereas those defined as nonresponders did not, would afford a rationale for our discrimination between responders and nonresponders. Although right heart catheterization in healthy subjects was not performed to evaluate the normal pulmonary vascular response to the cold stimulus, the report that PAP and PVR did not rise owing to the cold pressor test in normotensive subjects [20] indicates that pulmonary vasospasm is unlikely to be provoked in healthy subjects.

The temperature of the cold water could have affected the pulmonary vascular response in the present study. When the temperature was lowered in a stepwise manner, the levels of ET-1 at the onset of Raynaud's phenomenon $\left(18 \pm 2.3^{\circ} \mathrm{C}\right)$ were much lower than those at the complete loss of pulsality of the digital artery $\left(13 \pm 3.6^{\circ} \mathrm{C}\right)[10]$. In the present study, the temperature of the cold water was kept at $15^{\circ} \mathrm{C}$, in accordance with the former investigators, in order to compare data obtained under similar conditions. Thus, the cold pressor test performed at several different temperatures may elicit a different vascular response in the lung, which may be more useful in discriminating the heterogeneity as well as the major mediators.

All patients in the present study except for one were female. It is well known that female sex hormones influence vascular functions [28]. Oestrogen seems to possess beneficial effects on vasculature. Indeed, the incidence of cardiovascular events increases after menopause in females, which can be reduced by oestrogen replacement therapy [29]. Although the mechanisms of action of oestrogen are not yet fully understood, there are reports that oestrogen potentiates endothelium-dependent vasodilation of forearm artery in postmenopausal females [30, 31]. Such an effect may be attributable to the augmented production of NO [31] since oestradiol upregulates nitric oxide synthase (NOS) in endothelial cells [32]. However. it is unlikely that NO is the exclusive endothelium-derived vasodilator. Oestrogen induces a decrease in the formation of $\mathrm{TXA}_{2}$ [33], an increase in $\mathrm{PGI}_{2}$ formation [34] and an increase in the ratio of $\mathrm{PGI}_{2}$ to $\mathrm{TXA}_{2}[33,35]$. A calciumantagonistic effect on vascular smooth muscle cells has also been reported [36]. Progesterone, another female hormone, seems to antagonize the effects of oestrogen [28, 37]. Progesterone is unlikely to induce the NOS activity in endothelial cells [38] or the endothelium-dependent vasodilation [37], whereas it induces endothelium-independent relaxation, possibly be affecting $\mathrm{Ca}^{2+}$ influx [39]. However, there are still conflicting data on in vivo and in vitro effects of oestrogen and progesterone, which need to be elucidated further. Furthermore, female hormones may act diversely in the different vascular systems. For instance, oestradiol enhanced vasoconstriction due to the TX mimetic U-46619 in isolated rat lung [40]. Thus, it seems that there still exists a paradoxical association between female hormones and protection of some vascular diseases and susceptibility to others. The absence of effects of sex hormones, specifically oestrogen, in postmenopausal females may alter the vascular function in forearm and pulmonary circulations, which may have affected the results in the present study. From this point of view, two of five responders and five of eight female nonresponders were postmenopausal in the present study. The frequency of postmenopausal females was lower in responders than in nonresponders and there was no statistically significant difference between two groups as analysed by the Chisquared test. Therefore, it is unlikely that the factor of menopause affected the results. In this context, it is known that normal females have a variable response of digital blood flow to cold exposure and they are the least tolerant during menstruation [41], indicating that the influence of the menstrual cycle should be taken into consideration when performing the cold pressor test. However, the same authors also revealed that females with Raynaud's phenomenon never show such variation; thus, it is unlikely that the results of the present study were affected by the menstrual cycles in premenopausal patients.

$\mathrm{PGI}_{2}$ has been reported to improve survival in patients with PPH [42] and also improve cold tolerance and lessen Raynaud's phenomenon in patients with SSc [43]. The present data would provide an additional therapeutic rationale to use $\mathrm{PGI}_{2}$ in patients with Raynaud's phenomenon associated with MCTD or SSc as a prophylaxis of pulmonary vasospasm which otherwise may proceed to or enhance the remodelling of the pulmonary artery.

In conclusion, this study has shown that cold water hand-immersion induced pulmonary vasospasm in five of 14 patients with Raynaud's phenomenon associated with systemic sclerosis or mixed connective tissue disease. Increases in the level of 6-keto prostaglandin $F_{1 \alpha}$ and the ratio of 6-keto prostaglandin $F_{1 \alpha}$ to thromboxane $B_{2}$ in the mixed venous blood were observed in patients without pulmonary vasospasm but not in those with vasospasm. It was suggested that the impaired production of prostaglandin $I_{2}$ and the imbalance between prostaglandin $I_{2}$ and thromboxane $\mathrm{A}_{2}$ production are associated with Raynaud's phenomenon-induced pulmonary vasospasm. Although the precise mechanisms remain unclear, the changes in plasma prostaglandin $I_{2}$ and prostaglandin $I_{2} /$ thromboxane $A_{2}$ would at least serve as markers reflecting the pulmonary vascular responses to a cold stimulus in patients with Raynaud's phenomenon.

Acknowledgements. The authors thank A. Sakamoto and A. Yokote for excellent technical assistance, and M. Shiibashi for his assistance with statistical analysis.

\section{References}

1. Stupi AM, Steen VD, Owens GR, Barnes EL, Rodman GP, Medsger TA Jr. Pulmonary hypertension in the CREST syndrome variant of systemic sclerosis. Arthritis Rheum 1986; 29: 515-524.

2. Graziano FM, Friedman LC, Grossman J. Pulmonary hypertension in a patient with mixed connective tissue disease: clinical and pathological findings, and review of literature. Clin Exp Rheumatol 1983; 1: 251-255.

3. Cannon P, Hasson M, Case DP, Casarella WJ, Somners SC, LeRoy EC. The relationship of hypertension and renal failure in scleroderma (progressive systemic sclerosis) to structural 
and functional abnormalities of the renal cortical circulation. Medicine 1974; 53: 146.

4. Eliss WW, Baer AN, Robertson RM, Pincus T, Kronengerg MW. Left ventricular dysfunction induced by cold exposure in patients with systemic sclerosis. Am J Med 1986; 80: 385392.

5. Rich S, Dantzker DR, Ayres SM, et al. Primary pulmonary hypertension: a national prospective study. Ann Intern Med 1987; 107: 216-223.

6. Furst DE, Davis JA, Clements PJ, Chopra SK, Theofilopoulos AN, Chia D. Abnormalities of pulmonary vascular dynamics and inflammation in early progressive systemic sclerosis. Arthritis Rheum 1981; 24: 1403-1408.

7. Barr WG, Fahey PJ. Reduction of pulmonary capillary blood volume following cold exposure in patients with Raynaud's phenomenon. Chest 1988; 94: 1195-1199.

8. Shuck JW, Oetgen WJ, Tesar JT. Pulmonary vascular response during Raynaud's phenomenon in progressive systemic sclerosis. Am J Med 1985; 78: 221-227.

9. Serneri GGN, Gensini GF, Abbate R, et al. Impaired cardiac $\mathrm{PGI}_{2}$ and $\mathrm{PGE}_{2}$ biosynthesis in patients with angina pectoris. Am Heart J 1986; 112: 472-478.

10. Zsmora MR, O'Brien RF, Rutherford RB, Weil JV. Serum endothelin-1 concentrations and cold provocation in primary Raynaud's phenomenon. Lancet 1990; 336: 1144-1147.

11. Christman BW, McPherson CD, Newman JH, et al. An imbalance between the excretion of thromboxane and prostacyclin metabolites in pulmonary hypertension. N Engl J Med 1992; 327: 70-75.

12. Porter JF, Kingsland LC III, Lindberg DAB, et al. The AI/ RHEUM knowledge-based computer consultant system in rheumatology. Performance in the diagnosis of 59 connective tissue disease patients from Japan. Arthritis Rheum 1988; 31 : 219-226.

13. Subcommittee for Scleroderma Criteria of the American Rheumatism Association Diagnostic and Therapeutic Criteria Committee. Preliminary criteriafortheclassification of systemic sclerosis (scleroderma). Arthritis Rheum 1980; 23: 581-590.

14. American Thoracic Society. Single-breath carbon monoxide diffusing capacity (transfer factor). Recommendations for a standard technique. Am J Respir Crit Care Med 1995; 152: 2185-2198.

15. Baldwin E deF, Cournand A, Richards DW Jr. Pulmonary insufficiency, physiological classification, clinical methods of analysis, standard values in normal subjects. Medicine 1948; 27: $243-278$

16. Nishida O, Kambe M, Sewake N, et al. Pulmonary function in healthy subjects and its prediction, 5. Pulmonary diffusing capacity in adults. Jpn J Clin Pathol 1976; 24: 941-947. (in Japanese).

17. Yang SC, Yang SP, Lin PJ. Prediction equations for singlebreath carbon monoxide diffusing capacity from a Chinese population. Am Rev Respir Dis 1993; 147: 599-606.

18. Crapo RO, Morris AH. Standardized single breath normal values for carbon monoxide diffusing capacity. Am Rev Respir Dis 1981; 123: 185-189.

19. Powell WS. Rapid extraction of oxygenated metabolites of arachidonic acid from biological samples using octadecylsilyl silica. Prostaglandins 1980; 20: 947-957.

20. Kobayashi Y, Sakamoto Y, Shibasaki M, Kimura I, Matsuo H. Human alveolar macrophages synthesize endothelins by thrombin. J Immunol 1997; 158: 5442-5447.

21. Fiorentini C, Barbier P, Galli C, et al. Pulmonary vascular overreactivity in systemic hypertension. A pathophysiological link between the greater and the lesser circulation. Hypertension 1985; 7: 995-1002.

22. Kahaleh B, Matucci-Cerinic M. Raynaud's phenomenon and scleroderma. Dysregulated neuroendothelial control of vascular tone. Arthritis Rheum 1995; 38: 1-4.

23. Kahaleh MB, Osborn I, LeRoy EC. Increased factor VIII/von Willebrand factor antigen and von Willebrand factor activity in scleroderma and in Raynaud's phenomenon. Ann Intern Med 1981; 94: 482-484.
24. Jubelirer SJ. Primary pulmonary hypertension. Its association with microangiopathic hemolytic anaemia and thrombocytopenia. Arch Intern Med 1991; 151: 1221-1223.

25. Hutton RA, Mikhailidis DP, Bernstein RM, Jeremy JY, Hughes GRV, Dandona P. Assessment of platelet function in patients with Raynaud's syndrome. J Clin Pathol 1984; 37 : $182-187$.

26. Imai T, Hirata Y, Emori T, Yanagisawa M, Masaki T, Marumo F. Induction of endothelin-1 gene by angiotensin and vasopressin in endothelial cells. Hypertension 1992; 19: 753-757.

27. Marsen TA, Simonson MS, Dunn MJ. Thrombin induces the preproendothelin-1 gene in endothelial cells by a protein tyrosine kinase-linked mechanism. Circ Res 1995; 76: 987-995.

28. White MM, Zamudio S, Stevens T, et al. Estrogen, progesterone, and vascular reactivity: potential cellular mechanisms. Endocr Rev 1995; 16: 739-751.

29. Stampfer MJ, Colditz GA, Willett WC, et al. Postmenopausal estrogen therapy and cardiovascular disease-ten-year follow-up from the Nurses' Health Study. N Engl J Med 1991; 325: 756-762.

30. Gilligan DM, Badar DM, Panza JA, Quyyumi AA, Cannon RO III. Acute vascular effects of estrogen in postmenopausal women. Circulation 1994; 90: 786-791.

31. Kawano H, Motoyama T, Kugiyama K, et al. Gender difference in improvement of endothelium-dependent vasodilation after estrogen supplementation. $\mathrm{J}$ Am Coll Cardiol 1997; 30: 914-919.

32. Hishikawa K, Nakaki T, Marumo T, Suzuki H, Kato R, Saruta T. Up-regulation of nitric oxide synthase by estradiol in human aortic endothelial cells. FEBS Lett 1995; 360: 291293.

33. Henriksson P, Stege R, Gréen K. Profound decrease of in vivo formation of thromboxane during estrogen therapy. Eur $J$ Clin Invest 1996; 26: 1186-1188.

34. Mikkola T, Turunen P, Avela K, Orpana A, Viinikka L, Ylikorkala O. 17ß-Estradiol stimulates prostacyclin, but not endothelin-1, production in human vascular endothelial cells. $J$ Clin Endocrinol Metab 1995; 80: 1832-1836.

35. Fogelberg M, Vesterqvist O, Diczfalusy U, Henriksson P. Experimental atherosclerosis: effects of oestrogen and atherosclerosis on thromboxane and prostacyclin formation. Eur J Clin Invest 1990; 20: 105-110.

36. Zhang F, Ram JL, Standley PR, Sowers JR. 17ß-Estradiol attenuates voltage-dependent $\mathrm{Ca}^{2+}$ currents in A7r5 vascular smooth muscle cell line. Am J Physiol 1994; 266: C975C980.

37. Miller VM, Vanhoutte PM. Progesterone and modulation of endothelium-dependent responses in canine coronary arteries. Am J Physiol 1991; 261: R1022-R1027.

38. Goetz RM, Morano I, Calovini T, Studer R, Holtz J. Increased expression of endothelial constitutive nitric oxide synthase in rat aorta during pregnancy. Biochem Biophys Res Commun 1994; 205: 905-910.

39. Jiang CW, Sarrel PM, Lindsay DC, Poole-Wilson PA, Collins P. Progesterone induces endothelium-independent relaxation of rabbit coronary artery in vitro. Eur $J$ Pharmacol 1992; 211: 163-167.

40. Farhat MY, Ramwell PW. Estradiol potentiates the vasopressor response of the isolated perfused rat lung to the thromboxane mimic U-46619. J Pharmacol Exp Ther 1992; 261: 686-691.

41. Terregino CA, Seibold JR. Influence of the menstrual cycle on Raynaud's phenomenon and on cold tolerance in normal women. Angiology 1985; 36: 88-95.

42. Barst RJ, Rubin LJ, Long WA, et al. A comparison of continuous intravenous epoprostenol (prostacyclin) conventional therapy for primary pulmonary hypertension. $N$ Engl J Med 1996; 334: 296-301.

43. Wigley PM, Seibold JR, Wise RA, McCloskey DA, Dole WP. Intravenous iloprost treatment of Raynaud's phenomenon and ischemic ulcers secondary to systemic sclerosis. J Rheumatol 1992; 19: 1407-1414. 